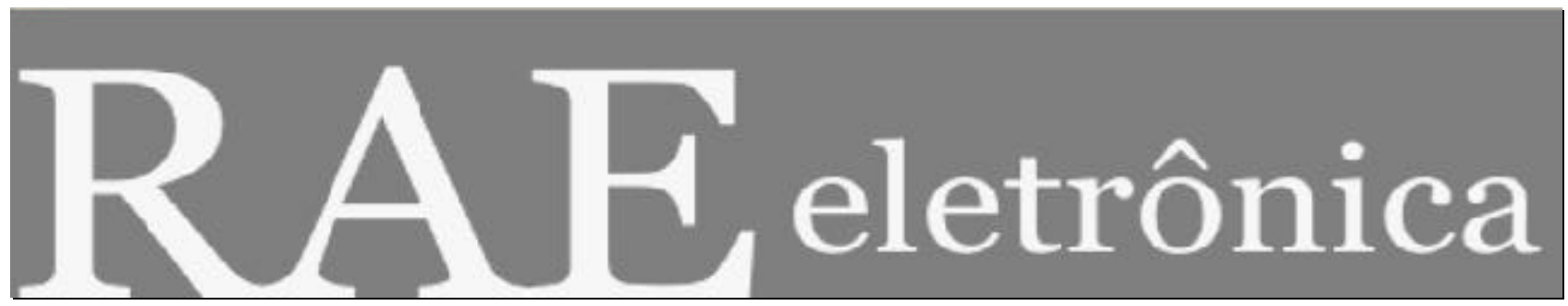

FÓRUM ESTUDOS CRÍTICOS EM ADMINISTRAÇÃO

\title{
PARTICIPAÇÃO COMO CONTROLE SOCIAL: UMA CRÍTICA DAS ESTRUTURAS ORGANIZACIONAIS FLEXÍVEIS
}

Por:

\section{João Marcelo Crubellate}

RAE-eletrônica, v. 3, n. 2, Art. 20, jul./dez. 2004

http://www.rae.com.br/eletronica/index.cfm?FuseAction=Artigo\&ID=1611\&Secao=FOR.ESTCRI\&V olume $=3 \&$ Numero $=2 \& A n o=2004$

CCopyright, 2004, RAE-eletrônica. Todos os direitos, inclusive de tradução, são reservados. É permitido citar parte de artigos sem autorização prévia desde que seja identificada a fonte. A reprodução total de artigos é proibida. Os artigos só devem ser usados para uso pessoal e nãocomercial. Em caso de dúvidas, consulte a redação: redacao@ rae.com.br.

A RAE-eletrônica é a revista on-line da FGV-EAESP, totalmente aberta e criada com o objetivo de agilizar a veiculação de trabalhos inéditos. Lançada em janeiro de 2002, com perfil acadêmico, é dedicada a professores, pesquisadores e estudantes. Para mais informações consulte o site www.rae.com.br/eletronica.

RAE-eletrônica

ISSN 1676-5648

(C2004 Fundação Getulio Vargas - Escola de Administração de Empresas de São Paulo.

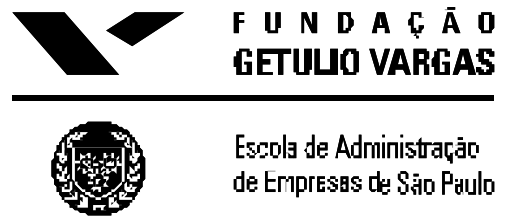




\title{
PARTICIPAÇÃO COMO CONTROLE SOCIAL: UMA CRÍTICA DAS ESTRUTURAS ORGANIZACIONAIS FLEXÍVEIS ${ }^{1}$
}

\section{RESUMO}

Este artigo tem por objetivo principal discutir criticamente a natureza do processo de dominação subjacente aos modelos altamente orgânicos típicos de estruturas organizacionais flexíveis. Tais modelos geralmente lidam com decisões complexas e de difícil formalização, o que para alguns autores implica a necessária e imediata democratização das organizações, que assumiriam estruturas consensuais, isentas de relações de poder. Com base no conceito de controle social, na sociologia da dominação weberiana e na idéia de racionalização do mundo da vida (HABERMAS, 1987), desenvolvemos uma definição de controle social normativo como processo de instrumentalização econômica das relações cotidianas convencionais dentro das organizações. Tal processo sugere nova ênfase sobre mecanismos informais de exercício do poder como resposta dos sistemas econômicos à potencial instabilidade em face de problemas inéditos e decisões não-estruturadas. Propõe-se assim outra via para interpretação do significado das estruturas participativas em organizações econômicas, uma interpretação que desconfia do otimismo predominante.

\begin{abstract}
The purpose of this paper is to discuss the process of domination in participative organizational structures. We use the concept of social control, the difference between social and bureaucratic ways of control and Habermas's idea of lifeworld's rationalization, to theoretically propose a definition of normative social control as a new way of controlling in participative organizational structures. We propose that normative social control refers to the institutionalization of economic purposive-rational orientation in the realm of personal informal relationships, and that it can be understood as a new emphasis upon ways of social domination and organizational control not based on rational-legal authority, but on the legitimacy of consensual decisions, in spite of the way consensus is reached. This kind of social control is understood here as an organizational reaction to the risk naturally implicated in participative decision-making processes, and as a key condition to the continuity of organizational systems that have to face complex decisions.
\end{abstract}

\section{PALAVRAS-CHAVE}

Controle social, racionalização, burocracia, participação, decisão.

\section{KEY WORDS}

Social control, rationalization, bureaucracy, participation, decision. 


\section{INTRODUÇÃO}

No âmbito da análise das mudanças e transformações organizacionais das últimas décadas, um dos temas bastante enfatizados refere-se à busca por evidências de supostos modelos alternativos às organizações burocráticas. Fora do círculo de literatura gerencialista, essa busca se caracteriza por objetivos muito mais descritivos que prescritivos, geralmente partindo da análise da obra weberiana sobre o tema e também concebendo o fenômeno da burocracia como poder social moderno e não como mera técnica administrativa.

De fato, a maior diferença entre prescrições gerencialistas e estudos de natureza sociológica, política ou mesmo da teoria organizacional parece estar em suas consequiências: as primeiras assumem geralmente a burocracia como modelo organizacional inapropriado para supostas novas características contextuais com que lidam as organizações. Já no segundo conjunto de estudos, ainda se discute a emergência de possíveis indícios de formas de organização social alternativas à burocracia (Dellagnelo e Machado-daSilva, 2000; Heckscher, 1994; Rothschild-Whitt, 1979). Ou seja, em tais contextos analíticos, por assim dizer, a burocracia continua "bastante viva". A despeito da fragmentação e das dificuldades da interpretação weberiana sobre burocracia e racionalização moderna, a sua desconsideração e a mera prescrição de supostas formas alternativas, sem fundamentação teórica e principalmente sem evidências empíricas, constitui-se recurso simplista de engenharia social de baixa qualidade, com pouca validade mesmo em termos práticos.

Pode-se supor então que a riqueza do tema exige abordagens analíticas e empíricas que tentem explorar as várias faces tanto do fenômeno da burocracia quanto de possíveis fenômenos paralelos ou alternativos, no intuito de construir conhecimento a partir da nova realidade social e organizacional que parece se configurar em face das profundas mudanças pelas quais atravessa a sociedade nas últimas décadas.

O presente texto faz opção por uma abordagem teórico-conceitual da questão, trabalhando o conceito de controle social e a crescente ênfase em uma de suas formas específicas - o controle social normativo - em organizações econômicas, como indício de transformações que vêm sendo entendidas como transição para um novo modelo social de poder e dominação. Especificamente busca-se neste artigo entender qual a natureza do processo de dominação subjacente aos modelos altamente orgânicos das novas estruturas organizacionais, que geralmente lidam com atividades altamente complexas e impossíveis de serem estruturadas formal e antecipadamente.

Supomos que o foco na análise do fenômeno do controle social não formal em organizações econômicas possa fornecer alternativas para entendimento da natureza política dos modelos estruturais altamente orgânicos, bem como fornecer evidências para sua interpretação como processo de dominação racional e portanto coerente com o processo de racionalização capitalista moderno, ainda que não fundamentado numa ordem legal.

Para tanto, discutiremos resumidamente o conceito de controle social no âmbito das teorias sociais e também no âmbito da teoria das organizações. Em seguida, resgatamos algumas das análises do fenômeno da burocracia que supõem sua superação em direção a modelos alternativos. A partir das definições sociológicas de controle social e da própria teoria de dominação weberiana, busca-se evidenciar um modo alternativo de controle social em organizações econômicas que entretanto seja 
ainda coerente com o processo de racionalização moderno baseado na calculabilidade e previsibilidade, em resposta à questão central proposta para o artigo.

Com base nessa resposta, buscamos por fim apontar possíveis fundamentos de uma definição do controle social normativo em organizações econômicas, situando o fenômeno no âmbito da noção habermasiana de colonização do mundo da vida e explorando algumas de suas consequiências para a interpretação dos processos organizacionais dentro de estruturas orgânicas e seus possíveis desdobramentos em termos de análise empírica da realidade organizacional.

\section{CONTROLE EM TEORIA SOCIAL: DOS FUNDAMENTOS DA NOÇÃO DE CONTROLE SOCIAL}

No âmbito da Sociologia, a noção de controle é geralmente delimitada como "controle social", referindo-se a processos de conformação do comportamento humano por meios diretos ou por meio das atitudes e significados que lhe são subjacentes. Para Meier (1982, p. 247), a noção de controle na teoria social contemporânea pode ser resumida na seguinte questão: "Quem deveria exercer controle sobre quem, como, e para quais fins?". Esses aspectos servem de parâmetro à teoria moderna do controle social e estão subjacentes às principais definições do fenômeno na teoria social. Percebe-se, contudo, que tal definição é ampla demais para possibilitar apropriada exploração tanto da ideologia subjacente( a que?) às definições de controle social quanto das várias tecnologias de controle predominantes na sociedade moderna.

Um dos primeiros sociólogos a definir sistematicamente controle social foi Edward Ross (1959, p.25), para quem, ainda que "[...] a maioria de nós ... nasceu com uma certa adequação para a ordem", a ordem social é algo que se deve construir, posto não ser característica natural da sociedade humana. "Há razões para acreditar que nossa ordem social [...] parece mais ser uma construção do que um desenvolvimento [natural]" (p.5). O escopo de sua obra indica claramente sua crença na necessidade de ordem para a existência ou conservação da sociedade, e nesse sentido o controle social emerge como a principal categoria de sua sociologia, se referindo aos esforços para moldar e adequar os sentimentos e desejos individuais às necessidades do grupo (COSER, 1982).

Coser (1982, p.13) conclui que a preocupação central de Ross recai sobre as “[...] instituições reguladoras que asseguram que o comportamento individual está de acordo com as demandas do grupo", referindo-se portanto não somente às estruturas políticas e coercitivas (sistema judiciário e polícia) mas também culturais (crenças no sobrenatural, cerimônias, opinião pública, sistemas morais, arte e educação). Há, portanto, uma semente institucional (não fica claro porque) no conceito de Ross, uma vez que o foco não está no comportamento do indivíduo em sociedade, mas em aspectos subjacentes à ação: sentimentos e desejos ou, atitudes e intenções, entendidos como sendo institucionalmente determinados.

A segunda tradição importante de teoria social sobre controle pode ser identificada com o funcionalismo em sociologia, fundamentada em Durkheim e culminando nos estudos de Parsons, com uma diferente definição de controle social: "[...] um sistema complexo de mecanismos não planejados e altamente inconscientes que servem para contrapor tendências desviantes" (PARSONS, 1951, p.321). Aqui a intencionalidade se torna inexistente porque o controle é percebido como processo altamente 
internalizado, um padrão costumeiro de respostas condicionadas por normas sociais. Como aponta Coser (1982, p.16) essa definição sugere que os seres humanos são "[...] executores passivos das agências estruturais e simbólicas de controle social". Outro aspecto central da definição está na legitimação do ponto de vista de grupos dominantes. Desviante é termo geralmente definido em função de normas, que por sua vez são padrões predominantes de comportamento e pensamento. Declarar desviante o que não coincide com o padrão predominante é negar a priori legitimidade a comportamentos alternativos e, conseqüentemente, a seus agentes.

Uma terceira corrente de entendimento do controle social está presente na literatura normativa que leva a extremos a noção de intencionalidade subjacente a todo poder e todo controle. Exemplos dessa abordagem são textos como "Admirável Mundo Novo" de Huxley e "1984" de Orwell, onde todo o controle é em essência ruim e toda sociedade é concebida como artificial e conscientemente planejada para benefício de alguns e controle total dos demais. Sua validade está no esforço de visualizar tipos ideais das sociedades totalitárias ao exagerar características negativas cujo potencial de realização encontra-se presente em todas as sociedades (COSER, 1982; MEIER, 1982). Assim, as mais recentes abordagens para o controle social se constroem com base em críticas às definições iniciais, de Ross e principalmente de Parsons. A questão que se apresenta como mais relevante no momento e que é pertinente a todas as atuais abordagens ao tema é: "Que interesses são servidos pelo controle social?" (GIBBS, 1982, p.246).

Turk (1982, p.251-252), por exemplo, propõe como definição de controle o "comportamento intencional para estabelecer e manter relações desiguais de benefícios", que se operacionaliza em termos da sociedade em uma "estrutura de autoridade - uma estrutura de desigualdades sustentada principalmente por poder ideológico, secundariamente por poder político e econômico, e só minimamente e ocasionalmente pela ameaça e uso da violência" (ainda que o autor não defina explicitamente essas diferentes formas de poder, elas estão implicitamente vinculadas - em seu texto com o uso de recursos normativos, materiais ou coercitivos, respectivamente, para reduzir a resistência às desigualdades). O "hardware" dessa estrutura de desigualdade se encontra em agências governamentais e instituições sociais. Esse esforço de controle, por sua vez, gera resistência intencional, provocando a necessidade de mais controle ou diferentes formas de controle, em dialética condicionada "[...] não só pelos propósitos e conhecimento das autoridades ao antecipar ou reagir a variadas formas de resistência, mas também pelo ambiente social em que o esforço de controle ocorre" (TURK, 1982, p.253). À intensidade e à natureza do controle correspondem portanto a intensidade do conflito e da resistência resultantes. Podemos inferir que o controle social, de natureza predominantemente ideológica, pode significar menor resistência sem que isso signifique ausência de poder e dominação ou mesmo de manipulação.

Outra forma de operacionalizar essa perspectiva institucional de entendimento do controle social é dada por Crane (1982, p.229) para quem "o conceito de controle social refere-se tanto à [manutenção da] ordem social [...] quanto ao consenso", onde ordem social refere-se à regulação do comportamento individual em sociedade por meio de instituições como leis, governo e polícia, e o consenso refere-se à difusão e compartilhamento de valores e percepções, fruto de instituições culturais como educação, religião, arte e ciência.

Já Gibbs (1982, p.86) ressalta o significado do termo social: o controle é social quando significa "[...] um esforço de um ou mais indivíduos [...] para manipular o comportamento de um ou mais indivíduos por meio de outro ou outros indivíduos [ou seja, de terceiros]”. Social, portanto, é uma forma específica 
de controle por meios indiretos que utiliza padrões convencionados no âmbito do grupo de referência a que pertencem os indivíduos que se pretenda controlar.

Os aspectos analisados até aqui, principalmente nas três últimas definições, permitem pensar o controle social como processo específico pelo qual ocorre a conformação do comportamento humano em sociedade para gerar determinada ordem social por meios indiretos, por meio das próprias pessoas implicadas no processo e também por meio de instituições sociais difusoras de padrões culturais, normativos e cognitivos. A teoria sociológica mais recente, portanto, vai caracterizar controle social como intencional (em variados graus) e manipulativo. Mas a intencionalidade, neste sentido e como sugere a definição de controle social em Gibbs (1982), acima mencionada (ver também MEIER, 1982) não pode ser inferida dos resultados do controle, senão apenas de seu processo. Isto é, a tendência é admitir que é pertinente à definição de controle social uma idéia de 'intenção em princípio', sem que se defenda que todas as conseqüências do controle social tenham sido intencionadas e planejadas previamente.

Ainda é necessário dizer que tais aspectos não são reconhecidos nas abordagens funcionalistas e, em conseqüência, em boa parte da teoria organizacional, claramente tributária àquela perspectiva paradigmática.

\section{DAS ORGANIZAÇÕES COMO INSTRUMENTOS DE CONTROLE SOCIAL AO CONTROLE SOCIAL NAS ORGANIZAÇÕES}

Uma das evidentes fontes de legitimidade da teoria organizacional como campo de estudo encontra-se no reconhecimento de que os padrões de conduta nos relacionamentos dentro das organizações influenciam o comportamento dos indivíduos em sua vida fora delas. Como afirma Motta (1979, p.11), as organizações tanto produzem bens e conhecimento como também são "[...] instâncias de controle a serviço de sistemas sociais maiores". Nesse sentido é que se pode entendê-las como instrumentos para o controle social, na medida que, no âmbito de seus relacionamentos internos, solidifiquem-se padrões de ação favoráveis à ordem predominante nas esferas sociais mais amplas.

Nessa perspectiva, os processos organizacionais não deveriam ser analisados apenas no seu aspecto técnico, como se fossem política e socialmente neutros. Como destaca Motta (1979), alguns autores vinculados à teoria organizacional funcionalista, interpretando o fenômeno da burocracia apenas como modelo organizacional, construíram propostas analíticas e prescritivas de controle organizacional baseadas em crítica das supostas disfunções da burocracia. Tais modelos em geral partiam de comportamentos ideais esperados e pressupunham corrigir distorções do modelo burocrático em direção àquele suposto ideal de organização. Facilmente se percebe que um dos erros estava na confusão quanto ao sentido da metodologia do tipo ideal em Weber. Em geral, nessas abordagens, o controle assumia conotação de necessidade natural (ver, por exemplo, TANNEMBAUM, 1968) sem discussão de seus pressupostos ou de suas conseqüências para indivíduos e grupos a ele submetidos.

O avanço da racionalização para fins econômicos parece implicar, entretanto, certa circularidade nesse processo, na medida que aumenta o poder das organizações capitalistas para interferirem nas demais instituições sociais e convertê-las em instâncias de institucionalização de padrões favoráveis à ordem econômica vigente. $\mathrm{O}$ avanço da modernidade (no sentido em que o discutem autores como GIDDENS, 
BECK e LASH, 1997, por exemplo) trás a legitimação do uso por organizações econômicas de técnicas e processos antes restritos a outras esferas ou espaços sociais, representando crescimento do espaço predominantemente econômico e a flexibilização de suas fronteiras, ao ponto de quase fluidez. Assim é que definir hoje o que pertence e o que não pertence a um espaço dito de predominância econômica é tecnicamente impossível, posto que instituições como educação, arte, religião e mesmo espaços como a intimidade se tornaram absolutamente marcados por, quando não condicionados para, objetivos econômicos, tanto quanto a organização se tornou também espaço para a educação, a arte, a religião e a intimidade, desde que se sujeitem à sua instrumentalidade econômica. No âmbito dessa ampla discussão podemos reconhecer uma dimensão organizacional e normativa do controle social que pretendemos especificar e situar teórica e criticamente neste artigo.

Noções embrionárias dessa transição podem ser encontradas já há algum tempo na teoria organizacional. Etzioni (1989), por exemplo, reconhece que a lógica puramente utilitária de controle não é única e nem necessariamente predominante nas organizações modernas. Para ele, os meios de controle podem ser fundamentados em três dimensões da vida humana, quais sejam a física, a econômica e a simbólica, esta última permitindo a constituição de uma forma de controle que ele denominou de "moral". Também Ouchi (1980) distingue três fontes de controle organizacional, sendo o terceiro deles chamado de controle de clã, que se manifesta no uso de cerimônias e símbolos para prescrição de valores e atitudes.

Nessas tipologias já se descortina a noção de controle normativo, sem relacioná-la contudo com processos de manipulação e considerando-a apenas no âmbito de uma suposta engenharia cultural interna às organizações. Como se pressupõe em geral que alguma forma de controle seja condição essencial para o que conhecemos como organização, ocorre a tendência de se naturalizar o fenômeno do controle, na medida que a organização é também reconhecida como fenômeno quase natural.

Retomando a crítica administrativa da burocracia, verifica-se que a análise das contradições da burocracia impulsionou mais recentemente uma série de críticas norteadas pela intenção de se decretar o seu fim como modelo organizacional e o esforço pela elaboração de modelos alternativos a ele, caracterizados principalmente por serem supostamente não hierárquicos e não dependentes de qualquer forma de poder e de dominação.

A imprecisão dessas análises e propostas e seu caráter altamente normativo vêm inspirando críticas bastante pertinentes, como as de Motta (1979) e de Dellagnelo e Machado-da-Silva (2000). O que sugerimos aqui é que uma diferente análise da burocracia mediante a exploração do conceito sociológico de controle social pode ajudar na construção de uma apropriada distinção entre os modelos estruturais altamente orgânicos e o modelo altamente burocratizado característico das organizações industriais. Pode também permitir a interpretação do significado político-ideológico subjacente àquelas estruturas orgânicas, isto é, das relações de poder e dominação nelas existentes, o que é geralmente desconsiderado, negado, ou mesmo abordado de modo exageradamente otimista nas análises correntes.

\section{FUNDAMENTOS DO CONTROLE BUROCRÁTICO}

Fora do círculo administrativo, burocracia foi geralmente entendida como forma de poder a que se vincula um modo específico de dominação e um instrumental específico que, por sua vez, se 
operacionaliza no mundo moderno principalmente por meio das organizações burocráticas. Dois equívocos marcam parte significativa da crítica administrativa da burocracia: considerá-la um modelo administrativo de natureza apenas técnica e supostamente neutra em termos políticos; e descontextualizar histórica e metodologicamente a análise weberiana da burocracia, interpretando tipo ideal como modelo prescritivo.

Para Gouldner (1971, p.61), “a incipiente distinção de Weber entre normas impostas e normas estabelecidas por acordo indica dois aspectos mais amplos de um mesmo problema, entrelaçados em sua teoria". Comentando essa afirmação, Motta (1979, p.19) conclui que ela "[...] acaba bem, mas começa muito mal: a distinção incipiente é nada mais nada menos do que a visão clara da manifestação da dominação mediante poder de mando e subordinação, e da dominação mediante uma constelação de interesses - uma transformando-se facilmente na outra".

Já sobre o tipo ideal, Weber (1993, p.137-138) é suficientemente claro ao apontá-lo não como uma prescrição, mas sim como recurso analítico ou, em outros termos, exagero proposital da realidade "[...] a fim de se formar um quadro homogêneo de pensamento. É impossível encontrar empiricamente na realidade este quadro, na sua pureza conceitual, pois trata-se de uma utopia".

Aqueles dois equívocos ofuscam o fato de que a burocracia como poder tem como conseqüência exatamente a legitimação de normas impostas e favoráveis a determinados interesses como se fossem normas acordadas e desprovidas de conteúdo político. Porém, se a organização burocrática é instrumento técnico, ela não é neutra; é "[...] tecnicamente o meio de poder mais altamente desenvolvido nas mãos do homem [...]" (WEBER, 1982, p.268). Como tal, fundamenta-se em uma forma específica de dominação que tem base em dois aspectos específicos: a racionalização instrumental subjacente e o seu caráter legal, sendo este último o aspecto que lhe confere legitimidade e estabilidade. Assim, a forma de legitimação da burocracia é tida como fruto de dominação do tipo racional-legal.

Dominação é " [...] a probabilidade de encontrar obediência para ordens específicas (ou todas) dentro de determinados grupos de pessoas. [...] a dominação ('autoridade') assim definida pode basear-se nos mais diversos motivos de submissão, desde o hábito inconsciente até considerações puramente racionais, referentes a fins" (WEBER, 1998, p.139). Mais especificamente, dominação "pode depender diretamente de uma constelação de interesses, ou seja, de considerações utilitárias de vantagens e inconvenientes por parte daquele que obedece" (p.128). Pode depender também do costume ou do afeto que gera inclinação pessoal do súdito à submissão.

Não é demais recordar que a burocracia implica dominação racional (instrumentalmente racional) e legal. Segundo Weber (1998, p.139-grifos meus): "Motivos puramente materiais e racionais referentes a fins da vinculação entre senhor e quadro administrativo significam [...] uma relação relativamente instável. [...] Mas nem o costume ou a situação de interesses, nem os motivos puramente afetivos ou racionais referentes a valores da vinculação poderiam constituir fundamentos confiáveis de uma dominação. Normalmente, junta-se a esses fatores outro elemento: a crença na legitimidade". A dominação legítima na burocracia é do tipo legal, e é a conjugação desses dois aspectos - o racional referente a fins e a legitimação por meios legais - que a caracterizam.

Quanto ao aspecto legal de dominação, a burocracia representa seu tipo mais puro, mas não único. Por dominação legal pode-se entender a situação em que se obedece "[...] não à pessoa em virtude de seu direito próprio, mas à regra estatuída, que estabelece ao mesmo tempo a quem e em que medida se deve obedecer" (WEBER, 2000, p.129). A obediência se dá, portanto, "de modo estritamente formal 
segundo regras racionais" (p.129) e "A vigência do contrato como base da empresa capitalista impõelhe o timbre de um tipo eminente da relação de dominação "legal'" (p.130). A norma na burocracia, portanto (e isso é essencial para a distinção do controle social no sentido aqui pretendido) é norma tornada estatuto, formalizada contratualmente.

Considerados esses aspectos gerais do fenômeno da burocracia, parece possível concluir que o controle burocrático significa a parametrização e subseqüente conformação do comportamento por meio de normas abstratas (isto é, formais), racionalmente estatuídas e legalmente legitimadas, implicando portanto em uma ordem que pode ser denominada "de direito" ${ }^{2}$ e dispondo conseqüentemente de um quadro de pessoas hierarquicamente estabelecidas para o fazer cumprir.

\section{CONTROLE BUROCRÁTICO E AS SUPOSTAS ALTERNATIVAS ÀS ORGANIZAÇÕES BUROCRÁTICAS}

Como analisa Rothschild-Whitt (1979) o controle em organizações burocráticas tem como um de seus principais mecanismos a referência a normas padronizadas. Mesmo quando se dá por supervisão direta, o padrão a ser averiguado no processo de supervisão não é pessoalmente determinado, mas sim formalizado de acordo com meios técnicos, sendo o supervisor apenas uma garantia de que o padrão formal está sendo cumprido pelo trabalhador.

Portanto, a lógica burocrática de controle pressupõe a possibilidade de antecipação do processo de trabalho, de suas consequiências e possíveis falhas. Para atividades altamente complexas, difíceis de se avaliar e difíceis de se simplificar, aquele pressuposto começa a ruir. Como apontam Tushman e Romanelli (1985, p.188), "para o trabalho que é difícil de avaliar e/ou planejar, controle pessoal e/ou burocrático devem ser suplementados com processos de controle social", que "[...] dependem da evolução de normas, valores e propósitos compartilhados que provêem uma linguagem comum, uma estrutura de referência e um conjunto de premissas a partir das quais complexas e sutis decisões podem ser tomadas mesmo na ausência de outras formas de controle".

Claramente se percebe que o controle social, do modo como entendido por Tushman e Romanelli (1985), dispensa a existência de quadro de pessoas formalmente definidas para o papel de fazer cumprir as normas exigidas, o que o diferencia de formas burocráticas (também sociais, em algum sentido) de controle. Esse aspecto, aliás, é destacado por vários autores (TUSHMAN e ROMANELLI, 1985; DAS e TENG, 2001, por exemplo) como a razão de sua ascensão como forma de controle organizacional predominante em contextos onde a complexidade do trabalho impede que ele possa ser planejado $a$ priori ou mesmo definido de modo heterônomo. À parte de uma discussão sobre o verdadeiro grau de autonomia sob processos de controle social, outro aspecto merece consideração, referente a que tipo de ordem social ele pressupõe.

Retornando à idéia de ordem em Weber (1998), tem-se que na burocracia a ordem caracteriza-se como "de direito". O tipo alternativo de ordem é a convenção, e ocorre quando "[...] sua vigência está garantida externamente pela probabilidade de que, dentro de determinado círculo de pessoas, um comportamento discordante tropeçará com a reprovação (relativamente) geral e praticamente sensível" (WEBER, 1998, p.21). A sua principal característica é que "em oposição ao direito [...] falta o quadro de pessoas especialmente ocupadas em forçar sua observação" (p. 21). Aparentemente, portanto, o 
controle social no sentido sociológico (GIBBS, 1982) e também no sentido dado por Tushmann e Romanelli (1985) está relacionado à ordem convencional, e não à ordem legal.

A ordem convencional não é abstrata e legal (formalizada no estatuto ou lei) mas informal e parcialmente personificada nos indivíduos, no próprio grupo ou em grupos de indivíduos enquanto representantes não oficiais dos padrões abstratos, em substituição ao estatuto. Tem correspondência, assim, com o tipo específico de controle social que aqui estamos considerando, cujo um dos aspectos é a conformação do comportamento em relação a normas informais, não estatuídas.

Entretanto, ordem convencional ou controle social não significam ausência de dominação, mas apenas uma forma diferente de dominação. Necessidades específicas de algumas formas de trabalho e de organização (extrema complexidade, imprevisibilidade, contexto institucional com aversão ao autoritarismo, demanda por participação) trazem alto grau de risco ao controle gerencial de processos de trabalho ou de resultados, senão mesmo a impossibilidade de sua utilização, como é o caso da tomada de decisão em relação a problemas técnica e politicamente complexos (MILLER, HICKSON e WILSON, 1996). Ora, quando se admite que o papel da gerência é essencialmente o de controlar (BRAVERMAN, 1987), percebe-se logo que aquelas novas necessidades implicam crise do papel gerencial.

Duas vias se mostram em relação à atuação da gerência: ou se admite sua impossibilidade de lidar com o novo contexto do trabalho, implicando a conseqüente admissão de formas comunitárias de organização onde os padrões realmente "emergem" do corpo coletivo de pessoas envolvidas (ROTHSCHILD-WHITT, 1979) e, aparentemente, a gerência perde qualquer função social, ou então se implementam formas de gerência intermediárias entre o exercício da autoridade legal e a autonomia parcial dos grupos não gerenciais. Supomos aqui que essa forma de controle social corresponda à segunda alternativa, portanto uma reação gerencial e capitalista às novas pressões ambientais sobre o trabalho.

A literatura que descreve novas alternativas organizacionais, por sua vez, vem enfatizando a construção de estruturas onde predominam uma racionalidade voltada a valores (ROTHSCHILD-WHITT, 1979; CLEGG, 1990), consenso e democratização (ROTHSCHILD-WHITT, 1979; HECKSCHER, 1994), mais democracia e menos burocracia (MINTZBERG, 1995). Tais alternativas recebem diversos nomes tais como coletividades, organizações flexíveis, adhocracias ou pós-burocracias, todas tendo como ponto comum a descrição de sua estrutura social como sendo altamente orgânica, com baixos graus de complexidade interna, de formalização e centralização (HATCH, 1997).

Para Heckscher (1994, p.3), por exemplo, um modelo pós-burocrático se caracterizaria principalmente quando os sistemas organizacionais "[...] colocam ênfase maior nas relações de influência do que nas relações de poder. Ou [...] buscam construir concordância entre pessoas com conhecimentos e interesses diversos não por meio de referência a um 'nível' [hierárquico] superior mas sim de discussão e persuasão". O cerne do fenômeno seria, então, a noção de concordância ou legitimidade consensual que, para aquele autor, resulta em democracia e tem como importante recurso o uso de diálogos institucionalizados.

Se, portanto, em relação à formalidade da ordem burocrática, um novo contexto organizacional parece emergir quando nos detemos na análise da atual evidência de um controle social não legal, deve-se contudo questionar se esse novo contexto implica todas as alterações que a literatura vem apontando, ou se temos configurado uma reação gerencial em direção a uma reordenação do trabalho e manutenção do status quo capitalista. Parece pertinente a crítica de Dellagnelo e Machado-da-Silva 
(2000): se a lógica predominante ainda é econômica, claramente o modelo de gestão adotado ainda será instrumental, mesmo que baseado em controle social, e qualquer grau de democracia não deixará de ser recurso bastante conveniente nas mãos da gerência.

Mas fora da esfera econômica haveria possibilidade de ocorrência de modelos organizacionais que superassem a lógica burocrática em direção a contextos real e plenamente participativos? Para Rothschild-Whitt (1979) essa possibilidade existe nos raros exemplos de organizações coletivistas, baseadas em autoridade cuja legitimidade se dá em função de racionalidade voltada a valores. Para a autora, tal modelo social não foi totalmente desconsiderado por Weber, mas foi tratado de forma marginal e vinculado à noção de carisma (ver também SCHLUCHTER, 1999). As características principais dessas organizações, segundo a autora, são a autoridade derivada do consenso, a quase inexistência de regras formais, a inexistência de carreiras, divisão de trabalho mínima e ausência de hierarquia, resultando em contexto socialmente igualitário, mesmo em relação à capacitação especializada para o trabalho. Em tais organizações o controle teria natureza essencialmente personalista e moral: além da seleção de pessoas com os mesmos valores da organização (seleção para homogeneidade) outros processos garantiriam a atuação democrática, tal como a participação coletiva e a negociação de decisões. Em outros termos, "essas organizações são coletivamente controladas por seus membros ou trabalhadores" (ROTHSCHILD-WHITT, 1979, p.512).Basicamente há muitas semelhanças entre essas características e as análises de outros autores. A diferença (bastante significativa, contudo) é que os exemplos daquela autora são todos de organizações não econômicas. Uma questão central parece então se colocar, referente à natureza contraditória entre capitalismo e posse coletiva da organização. O significado e as consequiências dessa contradição para a interpretação dos processos supostamente participativos e democráticos em organizações é o que buscamos explorar na parte final deste artigo, esperando fazer emergir uma possível interpretação do processo de dominação subjacente ao contexto das relações de trabalho internas das estruturas orgânicas mediante apontamentos para uma teoria do controle social normativo em organizações.

\section{APONTAMENTOS PARA UMA CRÍTICA DAS ESTRUTURAS ORGÂNICAS: EM DIREÇÃO A UMA DEFINIÇÃO DO CONTROLE SOCIAL NORMATIVO EM ORGANIZAÇÕES ECONÔMICAS}

Para alguns críticos da Modernidade a constatação generalizada da impossibilidade de controle racional das forças naturais e sociais significa, desde já, um abandono completo daquela intenção. Isso implicaria um estado de desorientação, um certo vácuo ou ausência de controle que teria, como resultado mais geral, a disseminação e generalização do risco, circunstância onde só a descontinuidade e o provisório seriam perenes. Beck (1997, p.24) declara, nesse sentido, que "em virtude de sua dinâmica independente e de seus sucessos, a sociedade industrial está escorregando para uma terra de ninguém [...]", escorregando para uma modernidade reflexiva, uma sociedade pós-industrial onde os vínculos institucionais tradicionais são quebrados, sem serem substituídos por quaisquer outros vínculos Nessas condições a ação torna-se liberta das "amarras" estruturais, porque o agente se torna capaz e demandado a refletir as próprias regras e recursos daquela estrutura (LASH, 1997a).

O resultado dessa circunstância inédita de superação de todas as tradições seria, para alguns, uma excessiva individualização e para outros, um estado generalizado de anomia, uma suposta sociedade de risco. Porém esses mesmo autores também destacam os limites do "descontrole" em âmbito mundial. 
Tem-se assim que "[...] a coalizão das empresas, dos políticos e dos especialistas, que criam os perigos da sociedade contemporânea, constrói um conjunto de discursos de isenção de tal responsabilidade. Assim fazendo, transformam os 'perigos' que eles próprios criaram em 'riscos' do tipo, por assim dizer, que fumantes ou jogadores assumem" (LASH, 1997b, p.239). Constituiu-se uma certa "irresponsabilidade organizada", a responsabilização apenas por parte daquele que assume a ação, sem qualquer parcela de culpa pelas instâncias criadoras da opção, no fluxo da democratização e da legitimação do individualismo. Mas essa parece ser apenas uma face do problema.

Luhmann (1998) também compartilha dessa suposição de risco e busca evidenciar a fluidez que se estabelece nas relações sociais por sua causa. Para ele, a força de toda autoridade foi superada no processo de desenvolvimento e racionalização dos sistemas sociais, sendo substituída pelo que se pode chamar de "políticas de entendimento", que seriam constantes esforços para negociar aspectos de discordância entre partes e superar provisoriamente (sempre) os entraves para a ação.

Na perspectiva dos sistemas sociais a negociação seria, na análise de Luhmann, algo de necessário exatamente pela ausência de qualquer outro meio disponível para legitimar certas ações, o que significa para ele o estabelecimento de circunstância onde os acordos são sempre provisórios. Por isso mesmo está implícita em sua análise a sugestão de que essa circunstância resulta em maior simetria de poder entre as partes envolvidas nos acordos, nas relações entre si e de si para com o sistema social ou a organização econômica quando for o caso, o que por sua vez tem como consequiência a disseminação do risco na sociedade visto que o sistema não possuiria mecanismos para antecipadamente garantir que as ações necessárias serão efetuadas e, portanto, garantir a priori sua continuidade.

Em certos aspectos, essa análise coincide com a perspectiva de teóricos organizacionais das estruturas flexíveis e do movimento de democratização organizacional, sem concordar com a visão otimista daqueles. Luhmann (1998) admite que política de entendimento não significa consenso, mas simples concordância provisória, isto é, não significa uma re-estabilização do sistema sobre novos fundamentos ou recuperação da autonomia e da razão da pessoa no âmbito dos sistemas. Ao contrário, implica para ele a superação de todo significado das relações cotidianas que não seja o econômico.

Habermas (2000, p.493) analisa da seguinte forma essa abordagem sistêmica da Modernidade: “[...] para Luhmann o mundo da vida perdeu desde já todo o significado na sociedade moderna diferenciada funcionalmente. [...] desaparece aquela interpenetração e oposição dos imperativos do sistema e do mundo da vida que explicam o caráter ambíguo da modernização social”. A ausência, portanto, de legitimidade para as instâncias sistêmicas funcionais (economia de mercado e Estado burocrático), que Luhmann toma como certa, é entendida por Habermas como conseqüência da expansão daqueles sistemas e sua invasão no mundo da vida: "[...] os processos de monetarização e de burocratização penetram nos domínios nucleares da reprodução cultural, da integração social e da socialização", e: "as opções obedecem à lógica de uma política alinhada aos imperativos sistêmicos econômicos e estatais" (HABERMAS, 2000, p.494). Portanto, o que para Habermas pode-se entender como ambigüidade ou disfunção, para Luhmann é fato inexorável, uma vez que os sistemas possuem a propriedade funcional de responder ao seu ambiente apenas de forma simplificada e limitada: um sistema econômico só pode responder economicamente às pressões de seu contexto (LUHMANN, 1989).

De fato, a análise proposta por Habermas implica reconhecer que a própria característica central do capitalismo é promover sempre uma tentativa de conciliar necessidades sistêmicas com o mundo da vida, propondo uma socialização dos bens por meio da diferenciação ou privatização da produção, irreconciliáveis por natureza: "Como resultado o sistema é constantemente confrontado com o dilema de ter que abstrair-se das regras normativas de ação e das relações de significado dos sujeitos [que 
regulam o mundo da vida] sem contudo ser capaz de despreza-las" (OFFE, 1984, p.85). A solução moderna para esse conflito é, nesta perspectiva, a racionalização do mundo da vida, sua tecnificação em função dos interesses e necessidades dos sistemas economicamente determinados.

As regras normativas, convencionalmente originadas, são em princípio alheias aos objetivos dos sistemas econômicos, como sugere Offe (1984) e colocam-se potencialmente como impedimento a interesses econômicos e burocráticos, porque não são (novamente: em princípio) originadas de planejamento consciente: "Em sociedades tribais a validade das normas sociais tem que ser mantida sem recurso a um poder de sanção do Estado. O controle social requer base religiosa, ancorada em forma de culto: violações das normas centrais do sistema de irmandade são tomadas como sacrilégio. A ausência das sanções externas é compensada por uma visão de mundo mítica que imobiliza o potencial discursivo para negação e inovação, pelo menos no domínio do sagrado" (HABERMAS, 1987, p.158-159, grifos meus). Nas sociedades modernas evidentemente as normas sociais adquirem caráter legal, sendo reguladas pelo Estado laico sem recorrência ao mito religioso, ou seja, por natureza e por tendência alheias à ordem convencional. Contudo, enquanto permanecer alguma força religiosa tradicional ou alguma relação moral e informalmente fundamentada, permanecerá algum grau daquela resistência ao novo e à superação das relações convencionais.

Essas barreiras são enfrentadas pelas organizações de modo específico e peculiar: "Organizações não somente se desconectam dos comprometimentos culturais [...]; elas também se fazem independentes dos contextos do mundo da vida mediante a neutralização dos fundamentos normativos dos contextos de ação informal, costumeira e moralmente regulados" (HABERMAS, 1987, p. 309). Mas como já sugeriu Offe (1984) os sistemas sociais não podem simplesmente desconsiderar essas relações convencionais, ainda que pretendam neutraliza-los. Define-se portanto a idéia de racionalização, tecnificação ou colonização do mundo da vida nos termos da explicação do modo pe lo qual se dá essa neutralização das relações convencionais pelas organizações, no modo pelo qual as organizações mesmas provêem para si a legitimação de que necessitam:

\footnotetext{
Organizações usam a neutralidade ideológica para escapar da força das tradições que de outro modo restringem o escopo e o soberano exercício de sua competência para delinear seus próprios programas. Assim como as pessoas são, enquanto membros das organizações, arrancadas das estruturas de personalidade e neutralizadas por meio da atribuição de padrões de desempenho, assim também tradições culturais e ideologias são roubadas de seu poder de união e convertidas em matéria-prima para os propósitos de planejamento ideológico, isto é, para um processamento administrativo das constelações de significado (HABERMAS, 1987, p.308309).
}

No âmbito de um conceito de controle social, portanto, a interpretação habermasiana de racionalização do mundo da vida pode ser entendida como um processo pelo qual o sistema econômico, notadamente as organizações econômicas, nutre intencionalmente uma ordem convencional conveniente aos seus objetivos, uma vez que não a pode simplesmente extinguir ou desconsiderar, porque tais padrões convencionais a afetam na sua capacidade de planejamento em direção à necessária calculabilidade e previsibilidade das ações. Aponta-se, portanto, para o esforço sempre presente de construção de uma ordem subjacente à aparente desordem ou igualitarismo das relações organizacionais, uma ordem favorável ao sistema e talvez ainda mais na medida que, diferentemente da ordem legal, explícita, seja menos passível de crítica porque menos consciente, da perspectiva das pessoas a ela submetidas, no tocante a seu caráter heterônomo ${ }^{3}$.

Se podemos admitir certa validade dessa construção teórica, podemos admitir também que a suposição de simetria de poder nos contextos de negociação e decisão em face de problemas complexos, isto é, 
onde aparentemente as forças saíram de controle, é artifício conveniente a um processo de dominação que mantém sobre novas bases uma situação de desigualdade, conveniente à construção de formas de controle "de baixo para baixo", do grupo sobre si mesmo mas não "para si mesmo", onde formas tradicionais "de cima para baixo" já não são legítimas ou eficientes. Se efetiva ou não, essa forma de dominação apontaria para a intenção de um controle social normativo, onde os indivíduos teriam ampliada sua liberdade de ação no âmbito de sua atuação na organização, mas exatamente porque no nível social - no âmbito da construção de sua socialização e no âmbito de suas relações cotidianas atuais - essa liberdade foi diminuída.

\section{CONSIDERAÇÕES FINAIS}

Controle social normativo é o conceito que aqui apresentamos no intuito de definir como se operacionalizam as tentativas das organizações econômicas de interferir nas relações cotidianas e informais dos indivíduos entre si e com as instituições sociais, para tornar funcional a seus objetivos a ordem convencional. Resumidamente diríamos que tal forma de controle possivelmente se evidencia mais fortemente quando a organização lida com problemas altamente complexos, não estruturados e não passíveis de estruturação por parte da organização, quando parte significativa do poder retorna aos indivíduos envolvidos no processo decisório e quando o risco de descontrole, isto é, de que as decisões não convirjam para os interesses centrais da organização ou dos grupos ocupando as estruturas formais de poder seja, em princípio, bastante elevado.

No seu escopo mais amplo, este artigo representa uma crítica da idéia de democratização das relações organizacionais, no que se refere a organizações econômicas. Acreditamos que contextos organizacionais supostamente democráticos caracterizam-se pela tentativa de lidar instrumentalmente com a construção do consenso social, is to é, intervir nos padrões sociais para torna-los condizentes e favoráveis aos resultados e objetivos intencionados pelos grupos de poder. Recentes discussões sobre gestão da cultura (como, por exemplo, GALLAGHER, 2002; ou CAMERON e QUINN, 1999) ou mesmo estudos sobre liderança (como em BENNIS, CUMMINGS e SPREITZER, 2001; ou BENNIS e NANUS, 1988) apontam para a realidade dessas intenções e para a validade da interpretação crítica que aqui propomos. No caso de companhias japonesas, freqüentemente referenciadas como exemplos de gestões baseadas no consenso, parece evidente que o que ocorre é a implementação de controle em outras dimensões externas à organização, de modo a conformar os indivíduos aos padrões necessários às organizações econômicas. Como destaca Barbosa (2001), competitividade, uniformização e conformismo são características individuais que, no Japão, são disseminadas desde a primeira socialização pelos pais, passando pelas escolas, vida universitária e culminando na entrada do indivíduo em alguma organização que se incumbirá de doutrinar o novo empregado de acordo com os valores que são convenientes ao trabalho. Note-se que, com todo esse aparato, certamente a necessidade de padrões externos de controle ou supervisão pessoal do trabalho se torna praticamente dispensável: o "consenso" já está garantido a priori. Mas admitimos que as implicações empíricas dessa forma de controle vão além desse esforço de interferência nos padrões de socialização primária. Devem ser encontrados também na relação entre organizações e outras instituições sociais (mudanças nas políticas educacionais, nas políticas relativas ao trabalho, por exemplo) e mesmo no processo discursivo interno às organizações, nas formas pelas quais a mera concordância (por várias razões que vão desde a ameaça de sanções até a simples resignação do indivíduo) se transforma, no âmago das estruturas orgânicas e das gestões participativas, em aparência de consenso. 
De fato, duas questões resumem as idéias aqui apresentadas: será que em contextos econômicos o controle social normativo não significa dominação de natureza manipulativa tão ou mais forte que controles de outra natureza, inclusive burocráticos? Será que realmente um maior grau de democratização nas relações organizacionais, sem a superação do caráter economicamente instrumental, merece a conotação positiva defendida por diversos autores organizacionais e significa a construção de consenso real?

O controle social do tipo que foi aqui definido parece implicar uma forma diferente de dominação, que não a racional-legal, e nesse sentido pode permitir entender a constituição de uma suposta organização social alternativa à burocracia. Mas controle social pode implicar, quando certos limites permanecem, a constituição de formas sutis e indiretas de exercício do poder, por constituir dominação não baseada em crença na legitimidade da norma formal mas, diríamos, crença na legitimidade do consenso sem necessariamente que haja de fato consenso. Desse modo, o controle social quando certos limites do sistema não são discutíveis ou negociáveis, constitui-se em recurso de controle, ainda que não burocrático, com evidente dominação dos envolvidos, em benefício de interesses definidos não consensualmente, a criação nas organizações de uma nova base de legitimidade, onde legitimidade já não havia.

O que se buscou ressaltar neste texto é que a ocorrência concomitante de controle social e razão economicamente instrumental pode até indicar um modelo alternativo, mas com certeza ele não tem correspondência com as coletividades, nem parece merecer o alto crédito em termos de autonomia individual que normalmente é dado aos processos participativos que ocorrem em algumas organizações. Corresponderiam a esse último exemplo as estruturas flexíveis ou adhocracias em grandes companhias econômicas, os projetos adhocráticos presentes no âmago de grandes burocracias, as estruturas constituídas para lidar com decisões referentes a problemas não estruturados.

Acreditamos que o cerne dessa discussão entre burocracia e modelos alternativos esteja na discussão de formas de dominação e de poder e na possibilidade de organização social sem dominação, isto é, formas de estabilização sem exercício de algum tipo de poder e sem algum tipo de privilégio garantido a priori.

Normalmente se recorre às idéias de consenso e de negociação como mecanismos para alcance daquelas supostas alternativas sociais, mas parece ser necessário que se detenha sobre a possibilidade de que tais mecanismos constituam, por fim, instrumentos retóricos de racionalização estratégica baseada em interesses previamente constituídos e em busca de novos fundamentos de legitimação. Enfim, que possam ser reduzidos a mais um recurso de dominação.

O desafio teórico, portanto, nos parece ser avançar na crítica das novas formas de gestão participativa e das novas formas de organização, no intuito de se conceber a possibilidade ou não de alguma forma de organização social que permita a ocorrência de consenso real ou válido (no sentido proposto por HABERMAS, 1997), quando a negociação não é apenas recurso para melhor alcance de objetivos complexos e difíceis, mas fato real e produto de intenções coletivas e da autonomia individual. Subjacente a isso está uma crítica à teoria organizacional e administrativa, quando pressupõe a possib ilidade de as organizações, principalmente organizações econômicas, se constituírem em espaços para plena realização humana. Lembram, afinal, aquela parábola cristã do remendo de pano novo costurado em roupa velha, que aumenta o tamanho do estrago na roupa. Um novo modelo organizacional talvez demande novo modelo de sociedade, sob o custo de que o estrago venha a ser maior! 
1 O autor agradece aos Professores Miguel Caldas e Flávio Vasconcelos pelas críticas e sugestões a uma versão preliminar deste artigo, bem como a dois avaliadores anônimos da RAE e aos coordenadores do Fórum de Estudos Críticos em Administração, também por suas críticas e sugestões.

2 A ordem de direito define-se "quando está garantida externamente pela probabilidade de coação (física ou psíquica) exercida por determinado quadro de pessoas cuja função específica consiste em forçar a observação dessa ordem ou castigar sua violação" (WEBER, 1998, p. 21).

3 Além disso, é de se supor que, uma vez que se faça ascender o domínio do econômico ao status de sagrado, ter-se-á instaurado o aproveitamento da força repressiva que é inerente às ordens convencionais religiosas para fins economicamente instrumentais, para além da instabilidade da ordem legal (como vimos em Weber).

\section{REFERÊNCIAS BIBLIOGRÁFICAS}

BECK, U. A reinvenção da política: rumo a uma teoria da modernização reflexiva. GIDDENS, A; BECK, U.; LASH, S. Modernização reflexiva. São Paulo: Unesp, 1997. p. 11-72.

BARBOSA, L. Igualdade e meritocracia. 3. ed. Rio de Janeiro: FGV, 2001.

BENNIS, W.; CUMMINGS, T.; SPREITZER, G. The future of leadership. New York: John Wiley, 2001.

BENNIS, W. e NANUS, B. Líderes. São Paulo: Harbra, 1988.

BRAVERMAN, H. Trabalho e capital monopolista. 3. ed. Rio de Janeiro: Guanabara Koogan, 1987.

CAMERON, K; QUINN, R. Diagnosis and changing organizational culture: based on competing values framework. New York: Addison-Wesley, 1999.

CLEGG, S. Modern organizations. London: Sage, 1990.

COSER, L. The notion of control in sociological theory. In: GIBBS, J. Social control. Beverly Hills: Sage, 1982. p. 13-22.

CRANE, D. Cultural differentiation, cultural integration, and social control. In: GIBBS, J. Social control. Beverly Hills: Sage, 1982. p. 229-244.

DAS, T. K.; TENG, B. T. Trust, control, and risk in strategic alliances: an integrated framework. Organization Studies, v. 22, n. 2, p. 251-283, 2001.

DELLAGNELO, E L.; MACHADO-DA-SILVA, C. Literatura sobre novas formas organizacionais: onde se encontram as evidências empíricas de ruptura com o modelo burocrático de organizações? In: ENCONTRO ANUAL DA ASSOCIAÇÃO NACIONAL DE PÓS-GRADUAÇÃO EM ADMINISTRAÇÃO, 24., 2000, Florianópolis. Anais... Rio de Janeiro: ANPAD, 2000. 1 CD-ROM. 
ETZIONI, A. Organizações modernas. 11. ed. São Paulo: Pioneira, 1989.

GALLAGHER, R. The soul of an organization: understanding the values that drive successful corporate cultures. Chicago: Dearborn Trade Pub., 2002.

GIBBS , J. (Org). Social control: views from the social sciences. Beverly Hills: Sage, 1982.

GIDDENS, A.; BECK, U.; LASH, S. Modernização reflexiva. São Paulo: Editora Unesp, 1997.

GOULDNER, A. Conflitos na teoria de Weber. In: CAMPOS, E (Org.). Sociologia da burocracia. 2. ed. Rio de Janeiro: Zahar, 1971. p. 59-67.

HABERMAS, J. O discurso filosófico da modernidade. São Paulo: Martins Fontes, 2000.

HABERMAS, J. The theory of communicative action - reason and the rationalization of society. Boston: Beacon Press, 1984.

HABERMAS, J. The theory of communicative action - lifeworld and system: a critique of functionalist reason. Boston: Beacon Press, 1987.

HATCH, M. J. Organization theory: modern, symbolic and postmodern perspectives. Oxford: Oxford University, 1997.

HECKSCHER, C. Defining the post-bureaucratic type. In: HECKSCHER, C.; DONNELLON, A (Eds). The post-bureaucratic organization: new perspectives on organizational change. California: Sage, 1994. p. 14-62.

LASH, S. A reflexividade e seus duplos: estrutura, estética e comunidade. In: GIDDENS, A.; BECK, U.; LASH, S. Modernização reflexiva. São Paulo: Unesp, 1997a. p. 135-206.

LASH, S. Réplicas e críticas: sistemas especialistas ou interpretação situada? Cultura e instituições no capitalismo desorganizado. In: GIDDENS, A; BECK, U; LASH, S. Modernização reflexiva. São Paulo: Unesp, 1997b. p. 207-254.

LUHMANN, N. Ecological communication. Chicago: University of Chicago, 1989.

LUHMANN, N. Observations on modernity. Stanford University, 1998.

MEIER, R. Prospects for control theories and research. In: GIBBS, J. Social control. Beverly Hills: Sage, 1982. p. 265-276.

MILLER, S.; HICKSON, D.; WILSON, D. Decision-making in organizations. In: CLEGG, S.; HARDY, C.; NORD, W. (Eds.). Handbook of organization studies. London: Sage, 1996. p. 293-312.

MINTZBERG, H. Criando organizações eficazes. São Paulo: Atlas, 1995.

MOTTA, F. P. Controle social nas organizações. Revista de Administração de Empresas, v. 19, n. 3, p. 11-25, 1979. 
OFFE, C. Ungovernability. In: HABERMAS, J. (Ed.). Observations on "The spiritual situations of the age”. Cambridge: Cambridge University, 1984. p. 67-88.

OUCHI, W. Markets, bureaucracies and clans. Administrative Science Quarterly, v. 25, p. 129-41, 1980.

PARSONS, T. The social system. New York: Free Press, 1951.

ROSS, Edward. Social control and the foundations of sociology. Boston: Beacon, 1959.

ROTHSCHILD-WHITT, J. The collectivist organization: an alternative to rational-bureaucratic models. American Sociological Review, v. 44, p. 509-527, 1979.

SCHLUCHTER, W. As origens do racionalismo ocidental. In: SOUZA, J. (Org.). O malandro e o protestante. Brasília: UnB, 1999. p. 55-120.

TANNENBAUM, A. O controle nas organizações. Petrópolis: Vozes, 1975.

TURK, A. Social control and social conflict. In: GIBBS, J. Social control Beverly Hills: Sage, 1982. p. 249-264.

TUSHMAN, M; ROMANELLI, E. Organizational evolution: a metamorphosis model of convergence and reorientation. Research in Organizational Behavior, v. 7, p. 171-222, 1985.

WEBER, M. Economia e sociedade. 3. ed. Brasília: UnB, 1998.

WEBER, M. Ensaios de sociologia. 5. ed. Rio de Janeiro: Guanabara Koogan, 1982.

WEBER, M. Os três tipos puros de dominação legítima. In: COHN, G. Weber. São Paulo: Ática, 2000. p. $128-141$.

WEBER, M. Metodologia das ciências sociais. São Paulo: Cortez, 1993.

Artigo aprovado em 24.10.2002. Aprovado em 28.11.2003.

\section{João Marcelo Crubellate}

Professor na Universidade Estadual de Maringá-UEM. Doutorando em Administração de Empresas na FGV-EAESP.

E-mail: jmcrubellate@aol.com

Endereço: Rua João Luis Dias, 545, B1. 2/303 - Maringá - PR, 87.023-130.

Interesses de Pesquisa: Teoria da organização. 